\title{
Preventive and therapeutic effect of intraportal oridonin on BALb/ c nude mice hemispleen model of colon cancer liver metastasis
}

\author{
Yu-Shen Yang^, Dan Wen^, Xue-Feng Zhao^ \\ Department of General Surgery, Dalian University Affiliated Xinhua Hospital, Dalian, China \\ Contributions: (I) Conception and design: X Zhao; (II) Administrative support: X Zhao; (III) Provision of study materials or patients: X Zhao; (IV) \\ Collection and assembly of data: Y Yang, D Wen; (V) Data analysis and interpretation: Y Yang, D Wen; (VI) Manuscript writing: All authors; (VII) \\ Final approval of manuscript: All authors. \\ Correspondence to: Xue-Feng Zhao. Department of General Surgery, Dalian University Affiliated Xinhua Hospital, No. 156 Wansui Street, Shahekou \\ District, Dalian, Liaoning 116021, China. Email: zoserbong@163.com.
}

\begin{abstract}
Background: This study is to investigate the preventive and therapeutic effect of intraportal oridonin on colorectal cancer liver metastasis (CRCLM).

Methods: The inhibitory effect of oridonin on HT29 cells was determined by CCK-8 and MTT assays. The preventive and therapeutic effect of intraportal oridonin on CRCLM were investigated by establishing BALb/c nude mice hemispleen models of colon cancer liver metastasis. The microscopic characteristics of tumor tissues were observed by hematoxylin-eosin staining, immunohistochemistry and TUNEL staining. On the other hand, liver function enzymes, such as alanine aminotransferase (ALT), aspartate aminotransferase (AST) and alkaline phosphatase (ALP), were detected to evaluate the hepatotoxicity of intraportal oridonin. The serum levels of tumor markers, including carcinoembryonic antigen (CEA) and $\alpha$-fetoprotein (AFP), were used to investigate the intervention effect of intraportal oridonin on CRCLM.

Results: Oridonin exerted an inhibitory effect on the proliferation of HT29 cells in vitro. Intraportal oridonin was found to effectively prevent the occurrence and formation of CRCLM, whilst intraportal oridonin can also exert a therapeutic effect on CRCLM. Additionally, liver enzymes testing indicated that intraportal oridonin possesses non-hepatotoxicity, instead can effectively alleviate liver injury caused by tumor. Furthermore, intraportal oridonin was also revealed to decrease the serum levels of AFP and CEA.

Conclusions: Intraportal oridonin can effectively inhibit the formation of liver metastatic tumor and exert a certain degree of preventive and therapeutic effect on CRCLM. These findings indicate intraportal oridonin to be a promising anti-metastasis agent for CRCLM.
\end{abstract}

Keywords: BALb/c nude mice; colon cancer liver metastasis; hemispleen model; intraportal oridonin; prevention and treatment

Submitted Oct 13, 2020. Accepted for publication Jan 27, 2021.

doi: $10.21037 /$ tcr-20-3042

View this article at: http://dx.doi.org/10.21037/tcr-20-3042

\section{Introduction}

Colorectal cancer (CRC) is one of the most commonly malignant tumors worldwide, and over one million new cases were confirmed yearly (1). Liver is the most common site of metastases from CRC, to which over half of CRC will metastasize (2). Nowadays, surgical treatment in combination with systemic chemotherapy provide the best chance of long-term survival for colorectal cancer liver metastasis (CRCLM) patients, with the overall median

^ ORCID: Yu-Shen Yang, 0000-0003-0310-3999; Dan Wen, 0000-0003-4257-0733; Xue-Feng Zhao, 0000-0002-4141-3990. 
survival of 3.6 (range: 1.7-7.3) years (3). Unfortunately, nearly $65 \%$ of patients may suffer a relapse after hepatectomy, the majority of which will thoroughly lose the opportunity of cure (4). Therefore, there is a great need to develop a novel way of postoperative adjuvant treatment for patients with CRCLM which can kill off residual micrometastasis, prevent the occurence of liver metastasis and decrease the metastatic recurrence rates.

Colon cancer cells spread to the liver mainly through the mesenteric veins and portal system. The newly growing liver metastases less than the size of $0.5 \mathrm{~mm}$ receive their blood supply via the portal branches, and they are supplied by hepatic artery until the size of micrometastasis is greater than $0.5 \mathrm{~mm}$ (5). Therefore, postoperative intraportal infusion chemotherapy could be an efficient way to prevent the occurrence and progression of liver metastases, by delivering higher concentrations of anticancer drug to local tumour cells at the initial phase of metastatic invasion. Intraportal 5-FU alone, or in association with other chemotherapy drugs in different schedules are the commonest. However, current results of these schedules are clinically inconclusive and remain controversial. Ramirez et al. (6). summarized the effect of intraportal 5 -FU from a few clinical trials and found that some trials have displayed a reduction in the hepatic recurrence rate without differences in overall survival, instead others have showed an increase in overall and disease-free survival with no benefit for the hepatic recurrences rates. These findings indicated that $5-\mathrm{FU}$ has a more limited value for patients with CRCLM undergoing postoperative intraportal infusion chemotherapy, the possible cause of which was the hepatotoxicity of 5-FU. Thus, finding a new drug with limited hepatic toxicity is extremely urgent.

Oridonin, a bitter tetracycline diterpenoid compound mainly isolated from Rhodamnia rubescens, displays many therapeutic effects, such as anti-inflammatory, neuroprotective, anti-bacterial, anti-neoplastic and antitumor effects (7). Recently, Shen et al. (8). indicated that oridonin exhibits antitumor activity by directly and allosterically inhibiting STAT3. Moreover, Kwan et al. (9). demonstrated that oridonin-induced apoptosis was associated with inhibited FAS and SREBP1 mRNA. So oridonin can block the development of malignant tumors through targeting multiple signaling pathways. However, to our best knowledge, there is no report about the preventive and therapeutic effect of intraportal oridonin on CRCLM. In the present study, we aimed to investigate the preventive and therapeutic effect of intraportal oridonin on
CRCLM by establishing BALb/c nude mice hemispleen model of colon cancer liver metastasis (CCLM). We present the following article in accordance with the ARRIVE reporting checklist (available at: http://dx.doi. org/10.21037/tcr-20-3042).

\section{Methods}

\section{Cell culture}

The human colon cancer cell line HT29 were purchased from American Type Culture Collection and cultured in RPMI-1640 medium (Gibco; Thermo Fisher Scientific, Inc.) supplemented with 10\% FBS (Invitrogen; Thermo Fisher Scientific, Inc.) and 1\% penicillin-streptomycin (Invitrogen; Thermo Fisher Scientific, Inc.) at $37^{\circ} \mathrm{C}$ in a humidified atmosphere under $5 \% \mathrm{CO}_{2}$.

\section{Cell viability and cytotoxic assays}

HT2 9 cells were seeded into a $96-$ well plate $\left(3 \times 10^{3}\right.$ cells/well) for $24 \mathrm{~h}$ at $37^{\circ} \mathrm{C}$ in an incubator under $5 \% \mathrm{CO}_{2}$, following which they were treated with different concentrations of oridonin ( 5 and $10 \mu \mathrm{mol} / \mathrm{L})$ for $24 \mathrm{~h}$. Cell viability was measured using Cell Counting Kit8 (CCK-8). CCK-8 $(10 \mu \mathrm{L})$ reagent (Beyotime Institute of Biotechnology) was then added to each well before a microplate reader (Bio-Rad Laboratories, Inc.) was used to measure the absorbance in each well at $450 \mathrm{~nm}$. Cell viability was calculated using the following formula: Ratio $(\%)=\mathrm{A}_{450}$ (study group) $/ \mathrm{A}_{450}$ (control group) $\times 100 \%$. A half maximal inhibitory concentration $\left(\mathrm{IC}_{50}\right)$ value was calculated as the concentration of oridonin that inhibited cell growth by $50 \%$.

HT29 cells $\left(3 \times 10^{4}\right.$ cells/well) were treated with the indicated concentrations of oridonin $(10 \mu \mathrm{mol} / \mathrm{L})$ for $12,24,48$ and $72 \mathrm{~h}$ before cell cytotoxicity was measured using the MTT assay. In total, $100 \mu \mathrm{L}$ MTT $(1 \mathrm{mg} / \mathrm{mL})$ was added into each well at $37^{\circ} \mathrm{C}$ and the absorbance was measured at $490 \mathrm{~nm}$ using an automated microplate reader (BioTek Instruments, Inc.). Cell inhibition rate $(\%)=\left(1-\mathrm{A}_{490}\right.$ test sample $/ \mathrm{A}_{490}$ control $)$ $\times 100 \%$.

\section{Hemispleen model}

A total of 30 female BALb/c nude mice (age, 6 weeks; weight range, $\sim 18-20 \mathrm{~g}$ ) were purchased from The Laboratory Animal Center of Dalian Medical University. 

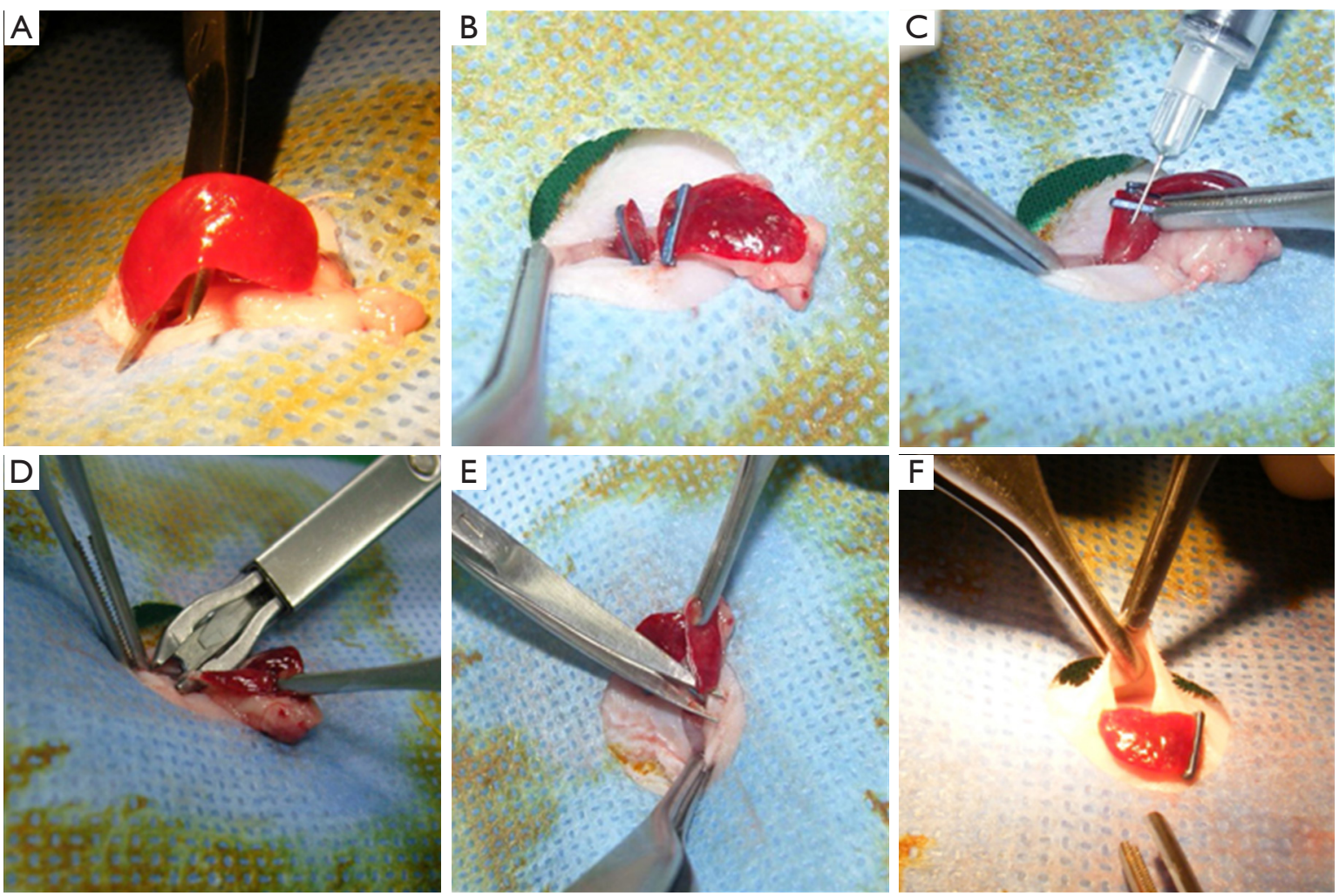

Figure 1 Modeling procedure. (A) Express the spleen through the incision. (B) Divide the spleen into two relatively equal parts, each with its own vascular pedicle. (C) Tumor Injection. (D) Ligate the vascular pedicle from the proximal hemispleen. (E) Remove the proximal hemispleen. (F) Transpose the distal hemispleen to a s.c.pocket with its vascular pedicle intact.

After 1 week of stabilization, hemispleen models were established by reference to the study of Kasuya et al. (10). and Soares et al. (11). After 12-h fasting with drinking water provided, these animals were firstly divided into blank control group $(n=6)$ and hemispleen model group $(n=24)$. All of mice were anesthetized with xylazine $(10 \mathrm{mg} / \mathrm{kg}) / \mathrm{ketamine}(70 \mathrm{mg} / \mathrm{kg})$ mixture. The toe pinch withdrawal reflex was abolished to demonstrate that the mouse was fully anesthetized. A median incision of upper abdomen $(\sim 1-1.5 \mathrm{~cm})$ was made through the skin and through the peritoneum using a scalpel. The spleen was exteriorized through the incision by applying simultaneous digital pressure along the cranial and caudal aspects of the incision. Then the spleen was split into two relatively equal parts, each with its own vascular pedicle, by placing two titanium clips in the center of the spleen. HT-29 human colon cancer cell lines suspension $\left(2 \times 10^{6} / 100 \mu \mathrm{L}\right)$ or Hank's balanced salt solution was slowly injected into the middle point of the proximal hemispleen of the mice in the hemispleen model or blank control group using 33-gauge needle, respectively. And a slight pressure was applied to compress the injection point with Surgicel for 10 minutes. Then the proximal hemispleen was removed from the abdominal cavity to prevent subsequent tumor growth in the spleen after its vascular pedicle was ligated by a titanium clip. And the distal hemispleen was transposed to a s.c.pocket with its vascular pedicle intact for the administration of oridonin. Additionally, the abdominal incision was closed step by step a few minute later (Figure 1).

Afterward, these mice in the hemispleen model group were then randomly divided into four subgroups according to the different time and components injected through spleen-portal vein ( $\mathrm{n}=6$ mice per group): (I) oridonin group for prevention $\left(7.14 \mathrm{mg} / \mathrm{kg}^{-1} \mathrm{~d}^{-1}, \mathrm{OD}-\mathrm{P}\right.$ group); (II) control group for prevention $(0.5 \%$ dimethyl sulfoxide, DMSO; Control-0D group); (III) oridonin group for treatment (OD-7.14 mg/kg. $\mathrm{d}^{-1}$, OD-T group); and (IV) control group for treatment (0.5\% DMSO, Control-2W group) (Table 1). Dosage administration of intraportal oridonin $\left(7.14 \mathrm{mg} / \mathrm{kg}^{\cdot} \mathrm{d}^{-1}\right)$ was determined according to our 
Table 1 The hemispleen model group names with the corresponding treatments

\begin{tabular}{lccc}
\hline Group & No. Mice & Administrating time & Treatment \\
\hline Control-OD & 6 & On the day of modeling & $0.5 \%$ DMSO \\
OD-P & 6 & On the day of modeling & $7.14 \mathrm{mg} / \mathrm{kg} \cdot \mathrm{d}^{-1} \mathrm{oridonin}$ \\
Control-2W & 6 & Two weeks after modeling & $0.5 \% \mathrm{DMSO}$ \\
OD-T & 6 & Two weeks after modeling & $7.14 \mathrm{mg} / \mathrm{kg} \cdot \mathrm{d}^{-1}$ oridonin \\
\hline
\end{tabular}

Control-OD, control group for prevention; control-2W, control group for treatment; OD-P, oridonin group for prevention; OD-T, oridonin group for treatment; DMSO, dimethyl sulfoxide.

preliminary experiment (Table S1). Repetitive portal venous injections of oridonin $\left(7.14 \mathrm{mg} / \mathrm{kg} \cdot \mathrm{d}^{-1}\right)$ via percutaneous injections into the s.c. hemispleen were performed in the blank control and OD-P group and the mice in the control$0 \mathrm{D}$ group received $0.5 \% \mathrm{DMSO}$ on the day of finishing models. Yet the other two groups for treatment were similarly treated after 2 weeks. After the administration of oridonin, the general condition of the model mice, consisting of active state, weight, fur color and mortality, were recorded once a day during the 2/4-week observation period. In order to minimize animal suffering before the experiment was over, mice were sacrificed by general criteria for euthanasia including pain that cannot be alleviated, notable loss of weight $(>20 \%)$, refusal to eat or drink, or abnormal general condition (auricles, feet, eyes and mouth mucosa turn blue) and behaviour (continuous convulsions, last gasping breath or making noises). All living mice were also euthanized to harvest the tumors four weeks after modeling, following which the extent of metastasis of mice in each group were recorded. Parameters, including liver quality, cured scars, depth of infiltration, necrosis of tumor and irregularly distributed cells were observed. All operations were performed under light microscopy (SZ61; Olympus Corporation, Tokyo, Japan). All animal experiments were approved by the Animal Ethics Committee of The Affiliated Xinhua Hospital Dalian University of Dalian in China (1905009), in compliance with all national or institutional guidelines for the care and use of animals.

\section{Blood sampling collection}

All mice were anesthetized with xylazine $(10 \mathrm{mg} / \mathrm{kg}) / \mathrm{ketamine}(70 \mathrm{mg} / \mathrm{kg})$ mixture at the end of the 4-week modeling period before blood samples $(\sim 0.2-0.4 \mathrm{~mL})$ were collected from the retroorbital plexus of each mouse. The absence of toe pinch withdrawal reflex was regarded as the parameters monitored to ensure that anesthesia induction was successful. The samples were then centrifuged $(10,000 \mathrm{rpm})$ for $20 \mathrm{~min}$ at room temperature, immediately aliquoted and processed on the same day.

\section{Macroscopic and microscopic analysis of pathology}

After blood samples collection, all of BALb/c nude mice from each group were sacrificed and assigned metastasis scores based on the following criteria: 0 , no liver metastasis; 1 , minimal infiltration $\left(<0.5 \mathrm{~cm}^{2}\right.$ area of metastasis $)$; 2, mild infiltration $\left(0.5-1.0 \mathrm{~cm}^{2}\right.$ area of metastasis); 3 , moderate infiltration $\left(1.0-2.0 \mathrm{~cm}^{2}\right.$ area of metastasis); 4 , severe infiltration $\left(>2.0 \mathrm{~cm}^{2}\right.$ area of metastasis) (12) (Figure 2). Then specimens from liver were fixed with $4 \%$ formaldehyde in PBS, dehydrated with ethanol, embedded in paraffin blocks, sectioned in $4 \mu \mathrm{m}$ increments and stained with hematoxylin-eosin staining (H\&E staining). The histological material and metastasis scores were assessed by two pathologists, and their findings were in concordance.

\section{Immunobistochemistry}

To assess cell proliferation, four-micrometer sections of the paraffin-embedded sections were stained for CK20 (DAKO, Tokyo, Japan). Fresh-frozen sections of the tumor tissue were deparaffinized, rehydrated in a graded series of alcohol and microwave-treated for $10 \mathrm{~min}$ in a citrate buffer (pH 6.0). Endogenous peroxidase activity was blocked using $0.3 \%$ hydrogen peroxide. Before immunostaining, antigen retrieval was performed by incubating the slides for $15 \mathrm{~min}$ with pepsin at a concentration of $1 \mathrm{mg} / \mathrm{mL}$ for CK20. The slides were incubated for $60 \mathrm{~min}$ with primary antibodies to CK20 (1:100) at room temperature. The avidin biotin immunoperoxidase technique was performed and diaminobenzidine was used as the chromogen. Sections were then counterstained with hematoxylin. The 

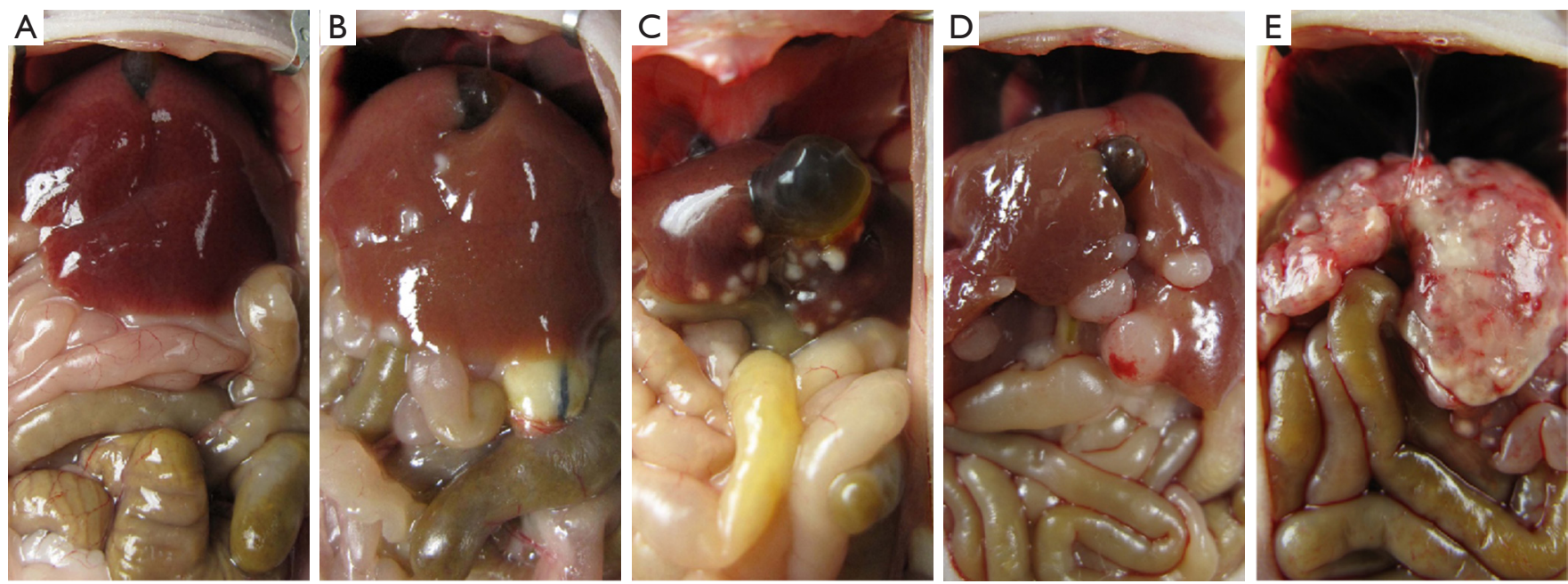

Figure 2 Determination of metastasis scores. (A) 0, no liver metastasis; (B) 1, minimal infiltration $\left(<0.5 \mathrm{~cm}^{2}\right.$ area of metastasis); (C) 2, mild infiltration (0.5-1.0 $\mathrm{cm}^{2}$ area of metastasis); (D) 3, moderate infiltration (1.0-2.0 $\mathrm{cm}^{2}$ area of metastasis); (E) 4, severe infiltration (>2.0 $\mathrm{cm}^{2}$ area of metastasis). Examples of mice receiving each score in representative images.

results of the bluish-violet were taken as an indicator of proliferative tumor cells. CK20 positive cells were counted in three random fields per slide and six slides each group were analyzed at 40/400× magnification (SZ61; Olympus Corporation). Cell death ratios were calculated using the following equation: cell death ratios $=(1-\mathrm{CK} 20$ positive cell number)/total tumor cell number. All the slides were examined independently by two pathologists, and their findings were in concordance.

\section{Terminal deoxynucleotidyl transferase (TdT) dUTP Nick- End Labeling (TUNEL) Staining}

Oridonin was found to kill malignant cells by inducing cellular apoptosis (13). TUNEL, as first described by Gavrieli (14), is an assay for localization of apoptotic DNA fragmentation in situ. Therefore, fresh-frozen sections of tumor tissues were tested by TUNEL staining according to the manufacturer's instructions. In situ cell apoptosis detection kit was purchased from Boster Biological Technology (Wuhan, Hubei, China). The results of the bluish-violet were regarded as an indicator of apoptotic cells. TUNEL-positive nuclei, a pyknotic nucleus with bluish-violet granules, were visualized and analyzed under a light microscope (SZ61; Olympus Corporation, 40/400×). Cell numbers were counted in 5 random fields and apoptosis indexes (AI) were calculated by the following equation as:
$\mathrm{AI}=$ positive cell number/total tumor cell number. All the slides were examined independently by two pathologists, and their findings were in concordance.

\section{Serum liver function enzymes}

To evaluate potential hepatotoxicity caused by intraportal oridonin, serum alanine aminotransferase (ALT), aspartate aminotransferase (AST) and alkaline phosphatase (ALP) were tested by using the Hitachi automatic biochemical analyzer (cat. no. 7600; HANGZHOU RUIXI TECHNOLOGY CO., LTD., Hangzhou, China).

\section{Tumor markers}

The expression of carcinoembryonic antigen (CEA) and $\alpha$-fetoprotein (AFP) was measured using an Roche fullautomatic immunoassay analyzer (cat. no. 601; Beijing Marin Medical Device Co., Ltd., Beijing, China).

\section{Statistical analysis}

SPSS version 20.0 software (IBM Corp., Armonk, NY, USA) was used for the statistical analysis of data. All results from measurement and ranked data in the present study were expressed as the mean $\pm \mathrm{SD}$. Comparisons between two groups of measurement data were assessed using 

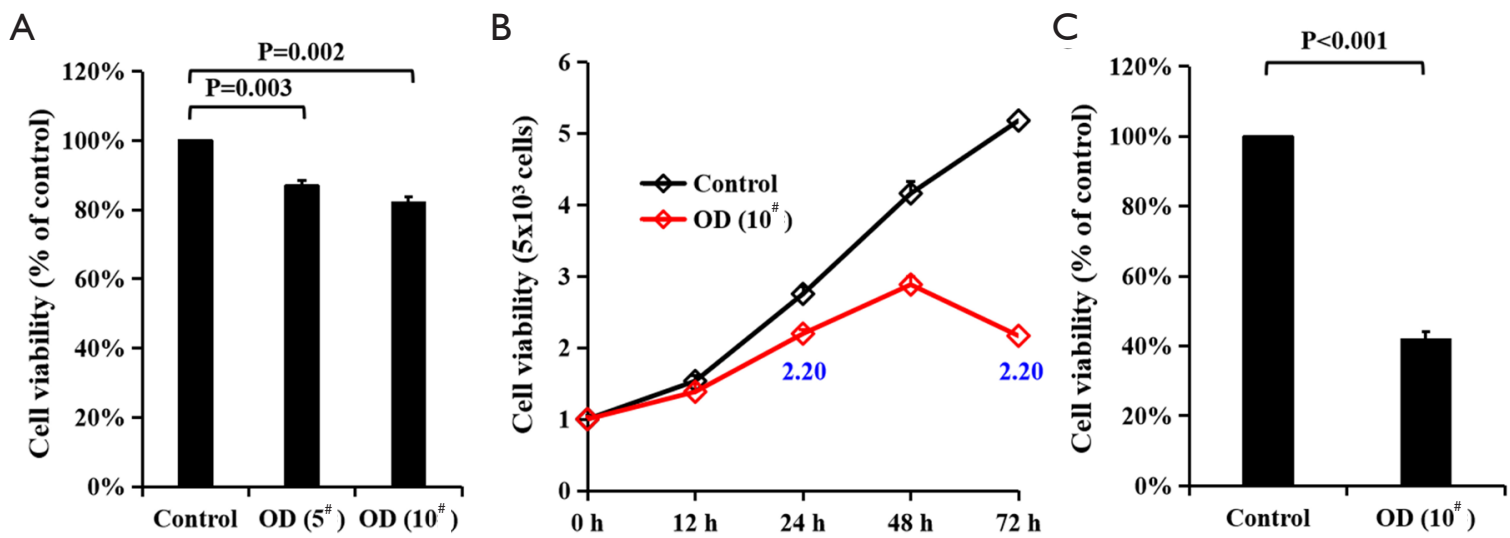

Figure 3 Inhibitory effect of oridonin on HT29 human colon cancer cells. (A) The inhibitory effects of oridonin on HT29 cells, as analyzed by CCK-8 assay. (B) The inhibitory effects of oridonin on HT29 cells, as analyzed by MTT assay. HT29 cells were treated with $10 \mu \mathrm{mol} / \mathrm{L}$ oridonin for $12,24,48$, and $72 \mathrm{~h}$. The inhibitory effects of oridonin were time-dependent. (C) This subfigure was taken at $72 \mathrm{~h}$ after the HT29 cells were treated. Values are the means \pm SD from three independent determinations. *, $\mu$ mol/L. OD, oridonin.

Student's $t$-test, whilst the one-way ANOVA followed by Bonferroni's post hoc test was used to evaluate statistical differences among multiple. Kruskal-Wallis test followed by Dunn's test was used to evaluate statistical differences of ranked data. Differences among multiple groups of categorical data were evaluated for significance using fisher's exact test followed by Bonferroni adjustment. $\mathrm{P}<0.05$ was considered to indicate a statistically significant difference.

\section{Results}

Oridonin exerts an anti-proliferative effect on HT29 buman colon cancer cells in vitro

HT29 cells were first treated with different concentrations of oridonin before cell viability was measured using CCK8 assay. It was found that oridonin reduced the viability of HT29 cells in a concentration-dependent manner $(\mathrm{P}<0.001$; Figure $3 A)$. The $\mathrm{IC}_{50}$ values of oridonin were calculated to be $30.309 \mu \mathrm{mol} / \mathrm{L}$ for HT29 cells. HT29 cells were next treated with $10 \mu \mathrm{mol} / \mathrm{L}$ oridonin before being subjected to cell cytotoxicity assays, where cell viability at different time points $(0,12,24,48$ and $72 \mathrm{~h})$ were analyzed. Oridonin was found to effectively reduce the cell viability of HT2 9 cells in a time dependent manner (Figure 3B), where it was demonstrated again that oridonin significantly exerted an inhibitory effect on HT29 cells (Figure 3C).

\section{Morphology manifestation of the preventive and therapeutic effect on CRCLM in vivo treated by intraportal oridonin}

A hemispleen model of CRCLM, generated by injecting HT29 human colon cancer cells into BALb/c mice, was used to test the efficacy of intraportal oridonin therapy in vivo. The success rates to establish the hemispleen model of human CRCLM were 100\% (24/24). Four weeks after modeling, the mice were euthanized and the livers were examined to determine the extent of tumor burden. The mice in the control-0D group had an average metastasis score of $3.33 \pm 0.52$. In contrast, OD-P group had an average metastasis score of $1.17 \pm 0.41$, indicating a significantly decrease in tumor burden in the treated mice for prevention. Mice in the control-2W and OD-T group had scores of $3.50 \pm 0.55$ and $1.83 \pm 0.75$, respectively, suggesting that a decrease in tumor burden can also be seen in the treated mice for treatment (Table 2, Figure 4). No lung and portal lymph node metastases were found in either group. Taken together, the mouse experiment showed morphologically that intraportal oridonin has an effect on the prevention and treatment of liver metastasis.

\section{Pathological characteristics of the preventive and therapeutic effect on CRCLM in vivo treated by intraportal oridonin}

The significant difference was not seen between the OD-P 
Table 2 Comparison of morphological and pathological difference between the mice treated with intraportal oridonin and the mice receiving control injection in hemispleen models

\begin{tabular}{|c|c|c|c|c|c|c|c|c|}
\hline Groups & Mice (n) & $\begin{array}{l}\text { Metastasis } \\
\text { score }\end{array}$ & $\begin{array}{l}\text { Liver weight } \\
\text { (g) }\end{array}$ & $\begin{array}{c}\text { Cured scars, } \\
(\%)\end{array}$ & $\begin{array}{l}\text { n Depth of infiltration } \\
\qquad(\mathrm{mm})\end{array}$ & $\begin{array}{l}\text { Cell death } \\
\text { ratios (\%) }\end{array}$ & $\begin{array}{l}\text { Apoptotic } \\
\text { index (\%) }\end{array}$ & $\begin{array}{l}\text { Irregularly distributed } \\
\text { cells, } \mathrm{n}(\%)\end{array}$ \\
\hline Control-OD & 6 & $3.33 \pm 0.52$ & $2.10 \pm 0.14$ & $0(0.0)$ & $1.20 \pm 0.18$ & $17.50 \pm 5.24$ & $14.17 \pm 3.66$ & $5(83.3)$ \\
\hline OD-P & 6 & $1.17 \pm 0.41^{*}$ & $1.57 \pm 0.10^{*}$ & $5(83.3)^{\star}$ & $0.27 \pm 0.10^{\star \#}$ & $60.83 \pm 8.01^{*}$ & $57.33 \pm 8.80^{*}$ & $2(33.3)^{\star}$ \\
\hline OD-T & 6 & $1.83 \pm 0.75^{\star}$ & $1.65 \pm 0.08^{\star}$ & $4(66.7)^{\star}$ & $0.40 \pm 0.09^{\star}$ & $58.33 \pm 11.69^{*}$ & $55.17 \pm 10.21^{*}$ & $2(33.3)^{\star}$ \\
\hline OD study groups & 12 & $1.50 \pm 0.67^{\star \star}$ & $1.61 \pm 0.10^{\star \star}$ & $9(75.0)^{\star \star}$ & $0.33 \pm 0.17^{\star \star}$ & $59.58 \pm 9.64^{\star \star}$ & $56.25 \pm 9.15^{\text {** }}$ & $4(25.0)^{\star \star}$ \\
\hline
\end{tabular}

Control-OD, control group for prevention; Control-2W, control group for treatment; OD-P, oridonin group for prevention; OD-T, oridonin group for treatment; Control groups, control-OD \& control-2W group; OD study groups, OD-P \& OD-T group. *, compared with Control-OD or Control-2W, $\mathrm{P}<0.05$; " , compared with OD-T, $\mathrm{P}<0.05$; ${ }^{* \star}$, compared with Control groups, $\mathrm{P}<0.05$.

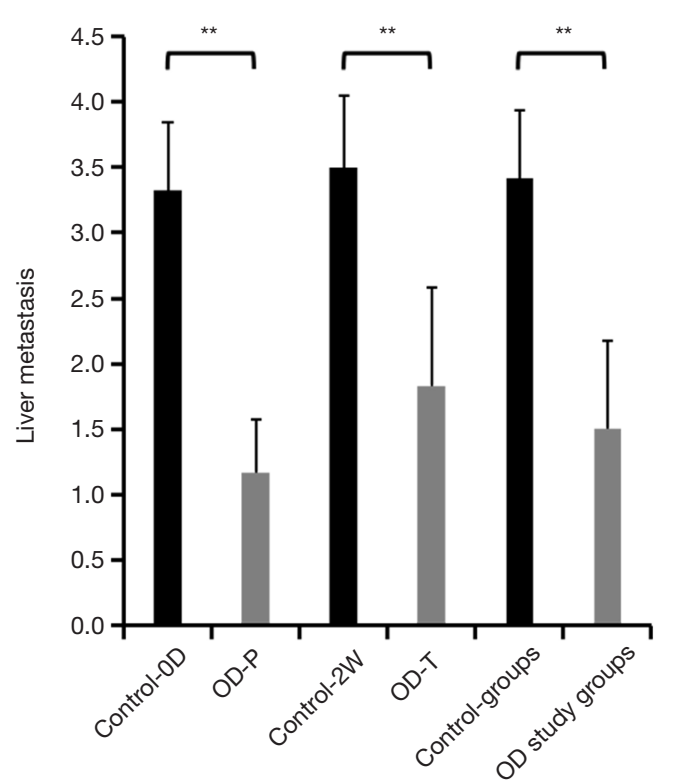

Figure 4 Liver metastasis scores. Values are the means \pm SD from three independent determinations. ${ }^{* *}, \mathrm{P}<0.01$, comparisons among multiple groups. Control groups, control-0D \& control2W group; OD study groups, OD-P \& OD-T group. Control0D, control group for prevention. Control-2W group, control group for treatment. OD-P group, oridonin group for prevention. OD-T group, oridonin group for treatment.

and OD-T group, whereas detected between the mice treated with intraportal oridonin and the mice receiving the control injection. Thus, in order to better understand the interventional effects of intraportal oridonin on CRCLM,
OD-P and OD-T group were fused into the OD study groups, meanwhile control-0D and control-2W group into the control groups. The statistical significance of the macroscopic and microscopic difference of pathology between the OD study and control groups were evaluated (Figure 5 and Table 2). When compared with control groups, OD study groups showed lighter liver quality $(2.05 \pm 0.20$ vs. $1.61 \pm 0.10 \mathrm{~g}, \mathrm{P}<0.05)$ and tumor infiltration $(1.20 \pm 0.15$ vs. $0.33 \pm 0.17 \mathrm{~mm}, \mathrm{P}<0.05)$ and less irregularly distributed cells $(83.3 \%$ vs. $25.0 \%, \mathrm{P}<0.05)$, whereas more cured scars $(0 \%$ vs. $75 \%, \mathrm{P}<0.05)$ and tumor cell death ratios $(17.92 \% \pm 4.98 \%$ vs. $59.58 \% \pm 9.64 \%, \mathrm{P}<0.05)$ (Figure $5 A, B, C, D)$. Metastatic liver nodules were confirmed histologically (Figure 5E,F,G,H). The inhibitory effect of intraportal oridonin on tumor cells proliferation was demonstrated by immunohistochemistry (Figure 5I,7,K,L). On the other hand, a small number of apoptotic cells were present in the tumors of the untreated control groups; however, a large number of bluish violet apoptosis was detected in tumors treated with the indicated concentrations of intraportal oridonin (Figure $5 M, N, O, P$ ). Additionally, compared with the control groups, intraportal oridonin significantly increased the values of AI $(15.42 \% \pm 3.96 \% v s$. $56.25 \% \pm 9.15 \%, \mathrm{P}<0.05$ ) (Table 2). These results suggested that intraportal oridonin inhibits tumor growth through the induction of apoptosis in vivo.

\section{Changes of liver enzymes and tumor markers}

After testing, there was a normal serum level of ALT 
Gross appearance

Morphologic characters
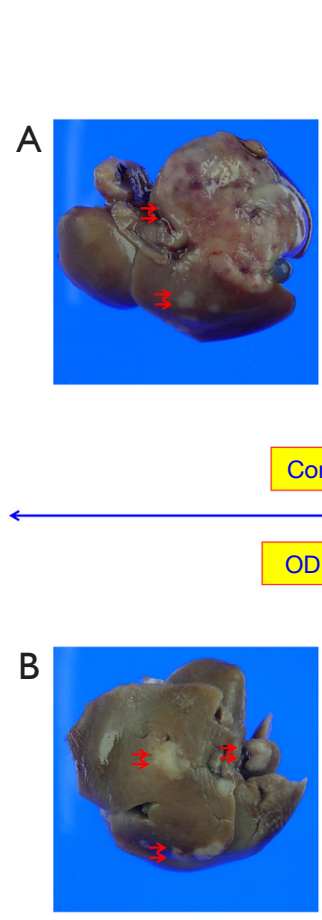

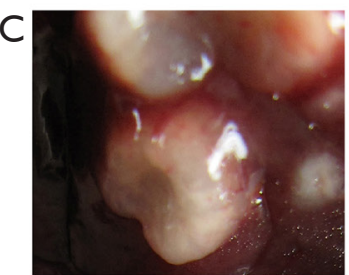

Control groups
$H \& E$

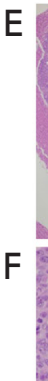

$\mathrm{F}$
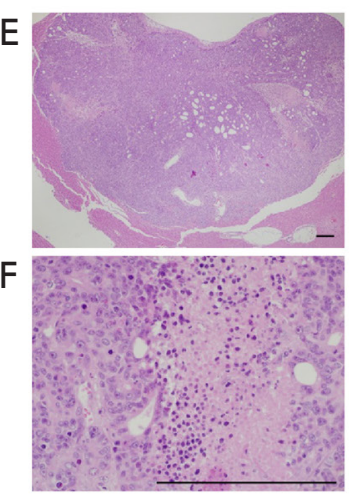

CK20

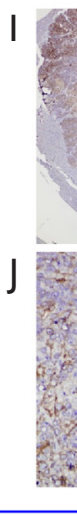

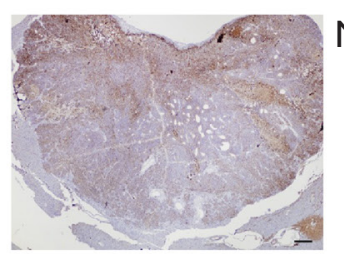

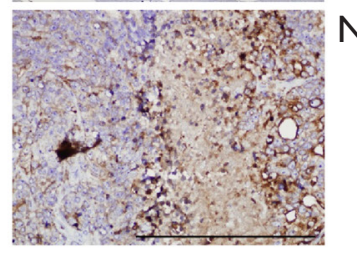

G

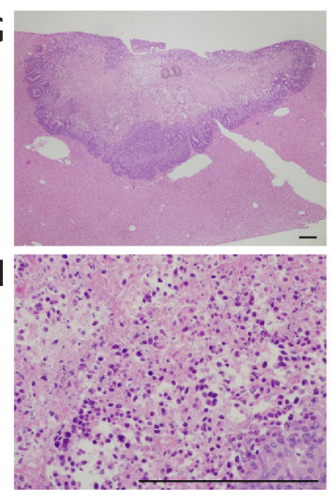

K

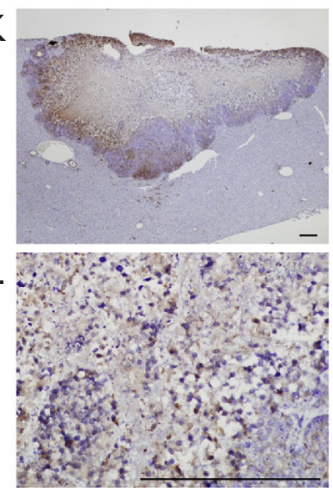

TUNEL

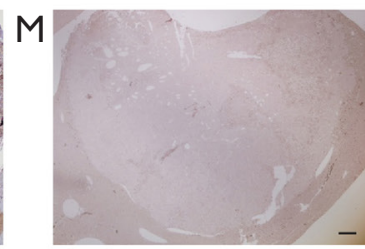

N
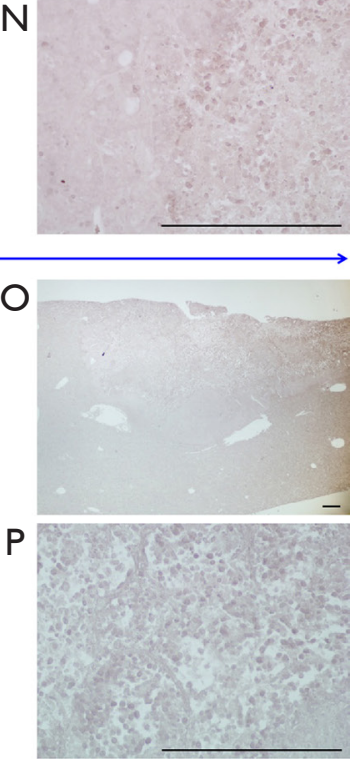

Figure 5 Intraportal oridonin inhibits tumor growth in hemispleen models. Scale bar $=100 \mu m$. OD, oridonin. H\&E, hematoxylin-eosin staining; CK20, Immunohistochemistry; TUNEL, Terminal deoxynucleotidyl transferase (TdT) dUTP Nick-End Labeling Staining.

$(10.17 \pm 3.764 \mathrm{U} / \mathrm{L})$, AST $(26.83 \pm 6.765 \mathrm{U} / \mathrm{L})$ and ALP $(54.17 \pm 16.485 \mathrm{U} / \mathrm{L})$ in the blank control group (15), while these indicators in other groups increased. Compared with control-0D group, serum ALT $(58.83 \pm 4.708$ vs. $43.00 \pm 6.033 \mathrm{U} / \mathrm{L}, \mathrm{P}<0.05)$ and AST $(83.00 \pm 11.967$ vs. $64.33 \pm 3.830 \mathrm{U} / \mathrm{L}, \mathrm{P}<0.05)$ levels in the OD-P group were revealed to be significantly lower. More interestingly, OD-P group also had a lower serum ALT $(43.00 \pm 6.033$ vs. $53.67 \pm 8.406 \mathrm{U} / \mathrm{L}, P<0.05)$ and AST $(64.33 \pm 3.830$ vs. $70.00 \pm 3.847 \mathrm{U} / \mathrm{L}, \mathrm{P}<0.05)$ levels than OD-T group. In addition, serum ALP levels were found to be markedly lower in the OD study groups compared with those in the control groups $(\mathrm{P}<0.05$ for both). The serum levels of AFP and CEA in the OD study groups were markedly lower compared with those in the control groups ( $\mathrm{P}<0.05$ for both). Moreover, an obvious reduction of serum AFP $(0.13 \pm 0.029$ vs. $0.21 \pm 0.029 \mathrm{ng} / \mathrm{mL}, \mathrm{P}<0.05)$ and CEA $(4.40 \pm 0.374$ vs. $5.87 \pm 0.398 \mathrm{pg} / \mathrm{mL}, \mathrm{P}<0.05)$ levels was seen in the OD-P group than that in the OD-T group (Table 3).

\section{Discussion}

Liver metastasis is the major reason of high mortality in patients with CRC (2). For a liver metastasis to form, cancer stem cells with metastatic potentiality must detach from the primary tumor, intravasate into portal system, travel in the circulation, extravasate from vessel, reattach to liver mesenchymal and develop into a new focus after the development of neovascularization (16). Thus, killing these cancer cells that have spread to liver and inhibiting the development of neovascularization become the keys to prevent the occurrence of CRCLM. Developing novel therapeutic agents that selectively kill cancer cells while sparing healthy cells and tissues will obviously increase the likelihood of achieving cure in patients with CRCLM. Although solitary primary CRC may be amenable to surgical treatment, metastatic disease is often incurable. Current efforts to treat metastatic CRC primarily dependent on radiotherapy and chemotherapeutic drugs, which may cause significant side effects, such as hepatotoxicity of 5-FU (17) 
Table 3 Effects of intraportal oridonin on liver enzymes and tumor markers in BALb/c nude mice serum of hemispleen model

\begin{tabular}{|c|c|c|c|c|c|c|}
\hline Groups & Mice, $\mathrm{n}$ & $A L T, U / L$ & AST, U/L & ALP, U/L & AFP, ng/mL & CEA, ng/mL \\
\hline Control-0D & 6 & $58.83 \pm 4.708$ & $83.00 \pm 11.967$ & $120.83 \pm 2.317$ & $0.71 \pm 0.092$ & $9.75 \pm 0.822$ \\
\hline Control-2W & 6 & $60.33 \pm 5.428$ & $81.17 \pm 15.092$ & $119.33 \pm 1.211$ & $0.70 \pm 0.100$ & $9.75 \pm 0.794$ \\
\hline OD-P & 6 & $43.00 \pm 6.033^{\star \#}$ & $64.33 \pm 3.830^{\star \#}$ & $109.67 \pm 4.412^{*}$ & $0.13 \pm 0.029^{\text {*\# }}$ & $4.40 \pm 0.374^{\text {*\# }}$ \\
\hline
\end{tabular}

Control-WT, blank control group. Control-OD, control group for prevention; Control-2W, control group for treatment; OD-P, oridonin group for prevention; OD-T, oridonin group for treatment; ALT, alanine aminotransferase; AST, aspartate aminotransferase; ALP, alkaline phosphatase; AFP, alpha-fetoprotein; CEA, carcinoembryonic antigen. *, compared with Control-0D or Control-2W, P<0.05; \#, compared with OD-T, $\mathrm{P}<0.05$.

and oxaliplatin (18), et al. Oridonin has been previously reported to confer a number of advantages compared with conventional anti-cancer agents, one of which is reduced toxicity. In a previous study, oridonin has been found to exhibit moderate cytotoxicity towards SGC7901 and SGC7901/DDP cells in vitro (19). In addition, oridonin has also been demonstrated to selectively induce tumor cell apoptosis without affecting other vital organs, including the bone marrow, liver and kidney (13). The similar result was obtained in the present study. Herein, in order to evaluate the hepatotoxicity of oridonin, the serum ALT, AST and ALP levels were tested among groups. Intraportal oridonin was demonstrated to possess non-hepatotoxicity by the normal serum levels of ALT, AST and ALP of mice in the blank control group (15). Intriguingly enough, the fact that there were lower serum ALT, AST and ALP levels in the groups treated by intraportal oridonin than in the control groups indicated that intraportal oridonin may effectively prevent liver injury from tumor and even have a certain protective effect on liver.

Previous studies have demonstrated that oridonin possesses a powerful anticancer effect on a large-scale cancer cell types, including breast cancers (20), non-small cell lung cancer (21), acute leukemia (22) and pancreatic cancer (23), et al. Recently, oridonin was also found to exert an anti-cancer effect on CRC by targeting BMP7/ p3 $8 \mathrm{MAPK} / \mathrm{p} 53$ signaling (24) and inhibiting glucose metabolism via downregulating the protein levels of GLUT1 and MCT1 (25). Meanwhile, oridonin displayed inhibitory effect on tumor growth and metastasis through anti-angiogenesis by blocking the Notch signaling (26). Therefore, oridonin can effectively kill off colon cancer cells through targeting multiple signaling pathways and inhibit the development of neovascularization. This finding was similar to our in vitro results that oridonin reduced the viability of HT29 cells in a concentration and time dependent manner. However, to our best knowledge, there is no report about the preventive and therapeutic effect of intraportal oridonin on CRCLM. In our hemispleen model, intraportal oridonin given on the day of finishing models seemed to effectively inhibit metastasis to the greatest extent. Although the mice receiving intraportal oridonin at two weeks after modeling seemed to have a larger metastatic liver nodules compared with those receiving an initial dose of oridonin on the day of finishing models, there was still an indication that they had a lower metastasis score compared with those that received the control injection at both times. On the other hand, the mice in the control-0D group had an average $\mathrm{AI}$ of $14.17 \% \pm 3.66 \%$. In contrast, OD-P group had a higher average AI of $57.33 \% \pm 8.80 \%$, indicating a large number of apoptotic cells were seen in the treated mice for prevention. Mice in the control-2W and OD-T group had AI of $16.67 \% \pm 4.18 \%$ and $55.17 \% \pm 10.21 \%$, respectively, suggesting that a significant increase in the apoptotic tumor cells can also be found in the treated mice for treatment. The ability of intraportal oridonin to inhibit metastasis whether given on the day or two weeks after modeling demonstrates that intraportal oridonin can kill both recently metastasized cells and established tumor cells by the induction of apoptosis, indicating that intraportal oridonin may be able to exert a preventive and therapeutic effect on CRCLM. Encouragingly, intraportal oridonin was found to possess more effective anti-metastasis effect on CRCLM than intravenous injection in our preliminary experiment (Figure S1).

Tumor markers are widely applied to evaluate tumor diagnosis, treatment and prognosis. Relative studies indicated that the levels of tumor markers can be changed 
before and after treatment, which may be associated with decreased tumor burden (27). Hence, finding effective tumor markers for the evaluation of therapeutic effect is very important for patients with CRC (28). Interestingly enough, $\mathrm{Hu}$ et al. revealed that the levels of TSGF, CEA and AFP obviously decreased one month after operation, indicating that radical resection for CRC can effectively alleviate the tumor burden in patients (29). Thus, CEA and AFP are proper tumor markers for the evaluation of therapeutic effect in patients with CRC. In the current study, the serum levels of AFP and CEA in the groups treated with intraportal were markedly lower compared with those in the control groups. It was also found that there were significant reductions in the levels of AFP and CEA in the OD-P group compared with those in the OD-T group. These findings suggested that intraportal oridonin effectively reduces the tumor burden, but unexpectedly, early prevention seem to be more effective than delayed treatment.

On the other hand, although complete resection of CRCLM is the best chance of cure, up to $85 \%$ of patients are unresectable at diagnosis (30). For the majority of CRC patients with unresectable liver metastasis, preoperative conversion chemotherapy is the most ideal option. The goals of conversion chemotherapy are to control the progression of liver metastasis, downsize the size of tumor to convert the unresectable to resectable and improve the sensitivity of tumor cells to chemotherapy drugs, etc. (31). In the current study, in order to simulate the liver environment after forming unresectable liver metastasis, oridonin and $0.5 \%$ DMSO were respectively injected into all of mice in the OD-T and Control-2W group through spleen-portal vein 2 weeks after modeling. The lower liver metastasis score in the OD-T group than that in the control-2W group $(1.83 \pm 0.75$ vs. $3.50 \pm 0.55, \mathrm{P}<0.05)$ suggested that intraportal oridonin seemed to alleviate metastasis to the greatest extent. Additionally, compared with control-2W group, there were lighter liver weight $(2.00 \pm 0.25$ vs. $1.65 \pm 0.08 \mathrm{~g}, \mathrm{P}<0.05)$ and tumor infiltration $(1.20 \pm 0.13$ vs. $0.40 \pm 0.09 \mathrm{~mm}, \mathrm{P}<0.05)$, whereas more cured scars $(0.0 \%$ vs. $66.7 \%, \mathrm{P}<0.05)$, tumor cell death ratios $(18.33 \% \pm 5.16 \%$ vs. $58.33 \% \pm 11.69 \%, \mathrm{P}<0.05)$ and $\mathrm{AI}(16.67 \% \pm 4.18 \%$ vs. $55.17 \% \pm 10.21 \%, \mathrm{P}<0.05)$ in the OD-T group, suggesting that intraportal oridonin can effectively downsize the size of tumor through the induction of apoptosis in vivo. More importantly, there were markedly lower serum levels of AFP and CEA in the OD-T group when compared with the control-2W group. Overexpression of CEA was found to induce 5-FU resistance (32), so blocking CEA using a CEA aptamer could enhance the sensitivity of CRC cells to 5-FU (33). These findings suggested that intraportal oridonin may also be able to improve the sensitivity of CRC cells to 5-FU by decreasing serum CEA levels. Hence, intraportal oridonin seem to provide a efficacious way for the preoperative conversion chemotherapy of the unresectable CRCLM.

However, the clinical application of oridonin is limited because of its low solubility, poor bioavailability (34) and rapid plasma clearance (35). Previously, surfactants and organic solvents were usually added in the injection formulation to overcome these drawbacks. For example, aminopterin was synthesized to induce remissions in children with acute leukemia using oridonin (36). But the unpredictable side effects of aminopterin such as mucosal toxicity, myelosuppressive effect, tumor lysis syndrome, etc., caused it to be withdrawn from the market in the early 1950s (37). Encouragingly, for purpose of overcoming the aforementioned disadvantages, recently many useful strategies have been explored including structural modification (38), new pharmaceutical formulations (39), nanoparticles (40), etc. It was reported that structural modification remarkably boosts its solubility and bioactivity (38), and the development of new dosage forms also promotes the regulation of oridonin delivery by pharmaceutics techniques (39). All these strategies chart a brighter course for the clinical application of oridonin.

\section{Conclusions}

In a word, this study firstly described the preventive and therapeutic effect of intraportal oridonin on CRCLM in vivo. Intraportal oridonin can effectively inhibit the formation of liver metastatic tumor, exert a certain degree of preventive and therapeutic effect on CRCLM and a protective effect on liver, but a further study need to be carried to clarify the specific anti-metastasis mechanism and reasonably present the quantitative index. Meanwhile, our group will also further determine whether intraportal oridonin improve the sensitivity of CRC cells to 5 -FU.

\section{Acknowledgments}

Funding: This study was supported by Liaoning Provincial Natural Science Foundations of China (grant nos. 201602037). 


\section{Footnote}

Reporting Checklist: The authors have completed the ARRIVE reporting checklist. Available at http://dx.doi. org/10.21037/tcr-20-3042

Data Sharing Statement: Available at http://dx.doi. org/10.21037/tcr-20-3042

Peer Review File: Available at http://dx.doi.org/10.21037/tcr20-3042

Conflicts of Interest: All authors have completed the ICMJE uniform disclosure form (available at http://dx.doi. org/10.21037/tcr-20-3042). The authors have no conflicts of interest to declare.

Ethical Statement: The authors are accountable for all aspects of the work in ensuring that questions related to the accuracy or integrity of any part of the work are appropriately investigated and resolved. All animal experiments were approved by the Animal Ethics Committee of The Affiliated Xinhua Hospital Dalian University of Dalian in China (1905009), in compliance with all national or institutional guidelines for the care and use of animals.

Open Access Statement: This is an Open Access article distributed in accordance with the Creative Commons Attribution-NonCommercial-NoDerivs 4.0 International License (CC BY-NC-ND 4.0), which permits the noncommercial replication and distribution of the article with the strict proviso that no changes or edits are made and the original work is properly cited (including links to both the formal publication through the relevant DOI and the license). See: https://creativecommons.org/licenses/by-nc-nd/4.0/.

\section{References}

1. Jemal A, Center MM, DeSantis C, et al. Global patterns of cancer incidence and mortality rates and trends. Cancer Epidemiol Biomarkers Prev 2010;19:1893-907.

2. Liu W, Wang HW, Wang K, et al. The primary tumor location impacts survival outcome of colorectal liver metastases after hepatic resection: A systematic review and meta-analysis. Eur J Surg Oncol 2019;45:1349-56.

3. Kanas GP, Taylor A, Primrose JN, et al. Survival after liver resection in metastatic colorectal cancer: review and meta-analysis of prognostic factors. Clin Epidemiol 2012;4:283-301.

4. Mayo SC, Pawlik TM. Current management of colorectal hepatic metastasis. Expert Rev Gastroenterol Hepatol 2009;3:131-44.

5. Archer SG, Gray BN. Vascularization of small liver metastases. Br J Surg 1989;76:545-8.

6. Ramirez LH, Munck JN, Bognel C, et al. Pharmacology and antitumour effects of intraportal pirarubicin on experimental liver metastases. Br J Cancer 1993;68:277-81.

7. Tan $W, \mathrm{Lu} J$, Huang $M$, et al. Anti-cancer natural products isolated from chinese medicinal herbs. Chin Med 2011;6:27.

8. Shen X, Zhao L, Chen P, et al. A thiazole-derived oridonin analogue exhibits antitumor activity by directly and allosterically inhibiting STAT3.J Biol Chem 2019;294:17471-86.

9. Kwan HY, Yang Z, Fong WF, et al. The anticancer effect of oridonin is mediated by fatty acid synthase suppression in human colorectal cancer cells. J Gastroenterol 2013;48:182-92.

10. Kasuya H, Kuruppu DK, Donahue JM, et al. Mouse models of subcutaneous spleen reservoir for multiple portal venous injections to treat liver malignancies. Cancer Res 2005;65:3823-7.

11. Soares KC, Foley K, Olino K, et al. A preclinical murine model of hepatic metastases. J Vis Exp 2014;(91):51677.

12. Hansen JE, Fischer LK, Chan G, et al. Antibody-mediated p53 protein therapy prevents liver metastasis in vivo. Cancer Res 2007;67:1769-74.

13. Owona BA, Schluesener HJ. Molecular Insight in the Multifunctional Effects of Oridonin. Drugs R D 2015;15:233-44.

14. Gavrieli Y, Sherman Y, Ben-Sasson SA. Identification of programmed cell death in situ via specific labeling of nuclear DNA fragmentation. J Cell Biol 1992;119:493-501.

15. WikiVet. Mouse Biochemistry. 2012. Available online: https://en.wikivet.net/Mouse_Biochemistry.

16. Jiang WG, Puntis MC, Hallett MB. Molecular and cellular basis of cancer invasion and metastasis: implications for treatment. Br J Surg 1994;81:1576-90.

17. El-Sayyad HI, Ismail MF, Shalaby FM, et al. Histopathological effects of cisplatin, doxorubicin and 5 -flurouracil (5-FU) on the liver of male albino rats. Int J Biol Sci 2009;5:466-73.

18. Ain NU, Bano N, Beg AE, et al. Hepatoprotective effects of ethanolic extract of Boerhaavia diffusa against oxaliplatin induced hepatotoxicity in albino rats. Pak J 
Pharm Sci 2019;32:1927-32.

19. He Z, Xiao X, Li S, et al. Oridonin induces apoptosis and reverses drug resistance in cisplatin resistant human gastric cancer cells. Oncol Lett 2017;14:2499-504.

20. Li Y, Wang Y, Wang S, et al. Oridonin phosphate-induced autophagy effectively enhances cell apoptosis of human breast cancer cells. Med Oncol 2015;32:365.

21. Wang YY, Lv YF, Lu L, et al. Oridonin inhibits mTOR signaling and the growth of lung cancer tumors. Anticancer Drugs 2014;25:1192-200.

22. Zhou GB, Kang H, Wang L, et al. Oridonin, a diterpenoid extracted from medicinal herbs, targets AML1-ETO fusion protein and shows potent antitumor activity with low adverse effects on $\mathrm{t}(8 ; 21)$ leukemia in vitro and in vivo. Blood 2007;109:3441-50.

23. Xu B, Shen W, Liu X, et al. Oridonin inhibits BxPC-3 cell growth through cell apoptosis. Acta Biochim Biophys Sin (Shanghai) 2015;47:164-73.

24. Liu RX, Ma Y, Hu XL, et al. Anticancer effects of oridonin on colon cancer are mediated via BMP7/p38 MAPK/p53 signaling. Int J Oncol 2018;53:2091-101.

25. Yao Z, Xie F, Li M, et al. Oridonin induces autophagy via inhibition of glucose metabolism in p53-mutated colorectal cancer cells. Cell Death Dis 2017;8:e2633.

26. Dong Y, Zhang T, Li J, et al. Oridonin inhibits tumor growth and metastasis through anti-angiogenesis by blocking the Notch signaling. PLoS One 2014;9:e113830.

27. Church D, Midgley R, Kerr D. Biomarkers in early-stage colorectal cancer: ready for prime time? Dig Dis 2012;30 Suppl 2:27-33.

28. de Cuba EM, Kwakman R, van Egmond M, et al. Understanding molecular mechanisms in peritoneal dissemination of colorectal cancer : future possibilities for personalised treatment by use of biomarkers. Virchows Arch 2012;461:231-43.

29. Hu Y, Wang JL, Tao HT, et al. Expression and significance of TSGF, CEA and AFP in patients before and after radical surgery for colon cancer. Asian Pac J Cancer Prev 2013;14:3877-80.

30. Chua TC, Saxena A, Chu F, et al. Predictors of cure after hepatic resection of colorectal liver metastases: an

Cite this article as: Yang YS, Wen D, Zhao XF. Preventive and therapeutic effect of intraportal oridonin on BALb/c nude mice hemispleen model of colon cancer liver metastasis. Transl Cancer Res 2021;10(3):1324-1335. doi: 10.21037/tcr-20-3042 analysis of actual 5- and 10-year survivors. J Surg Oncol 2011;103:796-800.

31. Abdalla EK. Commentary: Radiofrequency ablation for colorectal liver metastases: do not blame the biology when it is the technology. Am J Surg 2009;197:737-9.

32. Eftekhar E, Naghibalhossaini F. Carcinoembryonic antigen expression level as a predictive factor for response to 5-fluorouracil in colorectal cancer. Mol Biol Rep 2014;41:459-66.

33. Lee JH, Lee SW. Enhancement of chemosensitivity in 5-fluorouracil-resistant colon cancer cells with carcinoembryonic antigen-specific RNA aptamer. Mol Biol Rep 2019;46:3835-42.

34. Sun HD, Lin ZW, Niu FD, et al. Diterpenoids from Isodon eriocalyx var. laxiflora. Phytochemistry 1995;38:1451-5.

35. Yang YC, Wei MC. Kinetic and characterization studies for three bioactive compounds extracted from Rabdosia rubescens using ultrasound. Food and Bioproducts Processing 2015;94:101-13.

36. Farber S, Diamond LK. Temporary remissions in acute leukemia in children produced by folic acid antagonist, 4-aminopteroyl-glutamic acid. N Engl J Med 1948;238:787-93.

37. Farber S, Pinkel D, Sears EM, et al. Advances in chemotherapy of cancer in man. Adv Cancer Res 1956;4:1-71.

38. Xu J, Wold EA, Ding Y, et al. Therapeutic Potential of Oridonin and Its Analogs: From Anticancer and Antiinflammation to Neuroprotection. Molecules 2018;23:474.

39. Zhu L, Li M, Liu X, et al. Drug-Loaded PLGA Electrospraying Porous Microspheres for the Local Therapy of Primary Lung Cancer via Pulmonary Delivery. ACS Omega 2017;2:2273-9.

40. Feng N, Wu P, Li Q, et al. Oridonin-loaded poly(epsiloncaprolactone)-poly(ethylene oxide)-poly(epsiloncaprolactone) copolymer nanoparticles: preparation, characterization, and antitumor activity on mice with transplanted hepatoma. J Drug Target 2008;16:479-85. 


\section{Supplementary}

\section{Acute animal toxicity test}

According to the $\mathrm{LD}_{100}$ and $\mathrm{LD}_{0}$ from preliminary experiment, the administration dosage of oridonin was determined by a geometric series of 1:0.76 (21.40, 16.26, $\left.12.36,9.39,7.14,5.42,4.11,3.12,2.37,1.79 \mathrm{mg} / \mathrm{kg}^{-1} \mathrm{~d}^{-1}\right)$. 55 female and 55 male BALb/c nude mice (6 weeks of age, $18 \sim 20 \mathrm{~g})$ were purchased from The Laboratory Animal Center of Dalian Medical University (Dalian, China). All of BALb/c nude mice were randomly divided into 11 groups by their weight and sex: 10 dose groups of oridonin and a control group. $10 \mathrm{BALb} / \mathrm{c}$ nude mice were included in each group. After 12-hour fasting but drinking, different dose of oridonin or $0.5 \%$ dimethyl sulfoxide were respectively injected into all of mice in administered group or control group via intraspleen or intraportal vein. Then the common status including active state, weight, fur color, toxic reaction, death etc were recorded during the 2-weeks observation period. Last but not least, the half lethal dose $\left(\mathrm{LD}_{50}\right)$ was determined using probit analysis, meanwhile the maximum safe concentration of intraportal oridonin were determined, which was used as the dosage of subsequent treatment group and preventive group.

\section{The acute toxicity evaluation of intraportal oridonin}

To better pinpoint the toxicity, maximum safe concentration of intraportal oridonin, 11 groups of BALb/c nude mice were treated using the acute animal toxicity test. In order from top to bottom, all of BALb/c nude mice administrated with $21.4 \mathrm{mg} / \mathrm{kg} \cdot \mathrm{d}^{-1}$ oridonin via intraspleen or intraportal vein died during 2 weeks experiment. Then, $7.14 \mathrm{mg} / \mathrm{kg} \cdot \mathrm{d}^{-1}$ was the maximum dose in this experiment, where no mice died. Thus, the maximum safe dose of intraportal oridonin were respectively $7.14 \mathrm{mg} / \mathrm{kg} \cdot \mathrm{d}^{-1}$, which can be used as the administrated dose of treatment group and preventive group. On the other hand, $\mathrm{LD}_{50}$ of intraportal oridonin was calculated using probit analysis and it was $13.61 \mathrm{mg} / \mathrm{kg}^{-1} \mathrm{~d}^{-1}$ (Table S1).

Table S1 The acute toxic effect of intraportal oridonin on BALb/c nude mouse

\begin{tabular}{lccccc}
\hline Drug & Groups & Route of exposure & Dose $\mathrm{mg} / \mathrm{kg} \cdot \mathrm{d}^{-1}$ & Mortality & $\mathrm{LD}_{50} \mathrm{mg} / \mathrm{kg} \cdot \mathrm{d}^{-1}$ \\
\cline { 1 - 3 } oridonin & 1 & Intraspleen or & 21.40 & 10 & 13.61 \\
2 & intraportal & 16.26 & 8 & \\
3 & & 12.36 & 4 \\
4 & 9.39 & 1 \\
5 & 7.14 & 0 \\
6 & 5.42 & 0 \\
7 & 4.11 & 0 \\
8 & 3.12 & 0 \\
9 & 2.37 & 0 \\
\hline
\end{tabular}




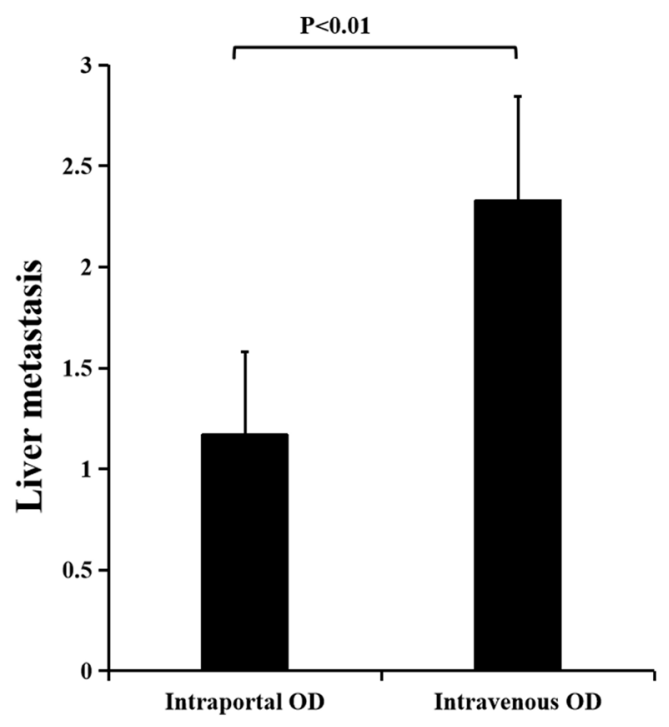

Figure S1 The comparison of liver metastasis scores between intraportal and intravenous OD. Values are the means \pm SD from three independent determinations. OD, oridonin. 